\title{
Everything that starry ain't leishmaniosis: Misleading presentation of cutaneous tuberculosis
}

\section{Khadija Issoual, Sara Dahhouki, Kaoutar Achehboune, Hanane Bay Bay, Sara Elloudi, Zakia Douhi, Fatima Zahra Mernissi}

\author{
Department of Dermatology, Hassan II Hospital University, Fez, Morocco
}

Corresponding author: Dr. Khadija Issoual, E-mail: khadijaissoual@gmail.com

\begin{abstract}
The dermoscopy of leishmaniasis is well described, it is characteristic and guides the diagnosis, we elucidate via a case of cutaneous tuberculosis, a clinical and dermsocopic aspect mimicking a leishmaniasis. we will confirm via this case the difficulty encountered in identifying the cutaneous tuberculosis and recognizing the clinical aspect and the dermocopic signs which are not specific in this affection. Cutaneous tubeculosis is a dilemma and a great simulator, it takes on several clinical aspects, it is always necessary to think about it and evoke before all the lesions of chronic evolution.
\end{abstract}

Key words: Cutaneous leishmaniosis; Tuberculosis; Dermoscopie

\section{INTRODUCTION}

Cutaneous tuberculosis (CTB) is an infectious dermatosis still endemic in Morocco, due to Mycobacterium Tuberculosis. Cutaneous localization is the fifth most common form of tuberculosis [1]. Clinical polymorphism and nonspecificity of dermoscopy make it difficult to diagnose. We reporting a case simulating Cutaneous Leishmaniasis.

\section{OBSERVATION}

A 39-year-old woman with no pathological history who was seen for an asymptomatic forearm lesion that had been evolving for 3 months, without any functional signs, with 3 other lesions in the legs. The dermatological examination had objectified a $2 \mathrm{~cm}$ nodule opposite the right wrist, purplish erythematous with a central ulcer crusted over (Fig. 1), and the presence of 3 plaques of less than $1 \mathrm{~cm}$ each, erythematous purplish, well limited, finely scaly on the 2 legs (Fig. 2). The dermoscopy of the nodule had objectified an erythematous fundus, a white starburst-like pattern and a central ulceration and a central ulceration (Fig. 3), and at the level of the legs; translucent orange globular areas, a white starburstlike pattern linear and hairpin telangiectasia vessels (Figs. 4a and 4b), with ulceration surmounted by crusts. The clinical and dermoscopic aspect was suggestive of an CL but the smear in search of leishmania body was negative. The pathological study revealed a tuberculoid granuloma with foci of caseous necrosis (Fig. 5). The diagnosis selected was the CTB. The patient was put on antituberculous treatment with good progress.

\section{DISCUSSION}

CTB is a difficult diagnosis to make, clinical and histological presentations depend on the immune status and cellular immunity of the patient [2]. However, no dermoscopic sign is characteristic or typical of this pathology. In our case, the clinic and the dermoscopy were very suggestive of CL, although the histology was in favor of CTB. Indeed, the exploded star aspect is quite suggestive of the CL, but it can be observed in some cases of CTB as illustrated by our observation [3]. CBT must be evoked in front of any chronic lesion in endemic countries. His diagnosis

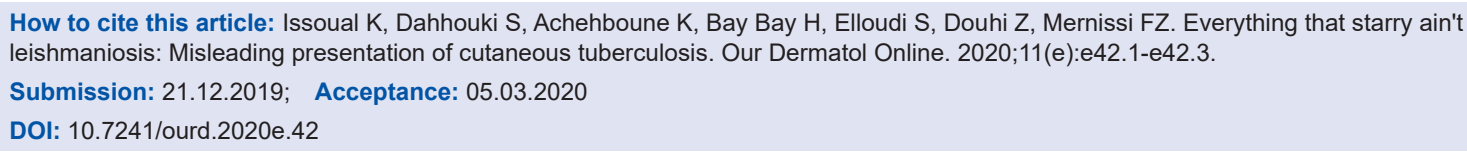




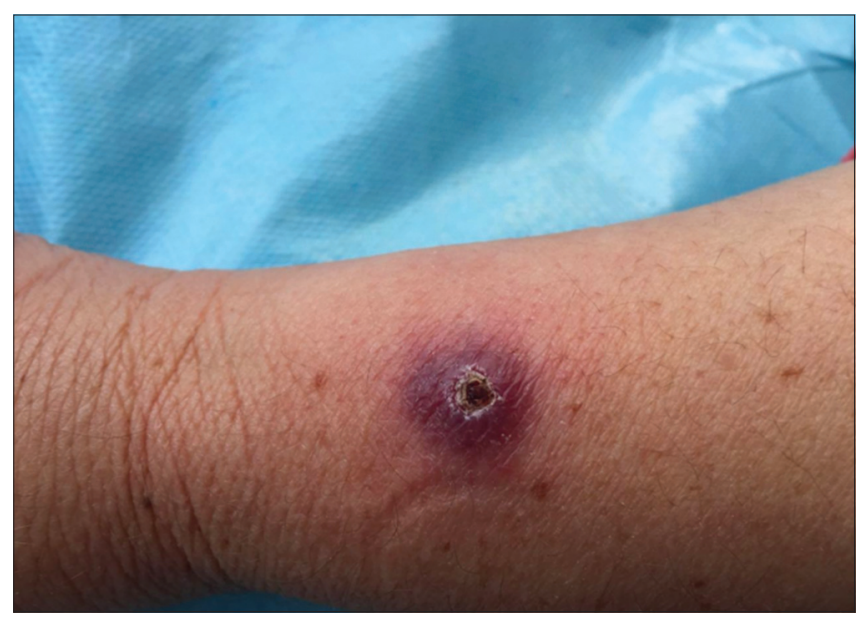

Figure 1: Nodule on the right wrist, erythematous with a central ulcer.

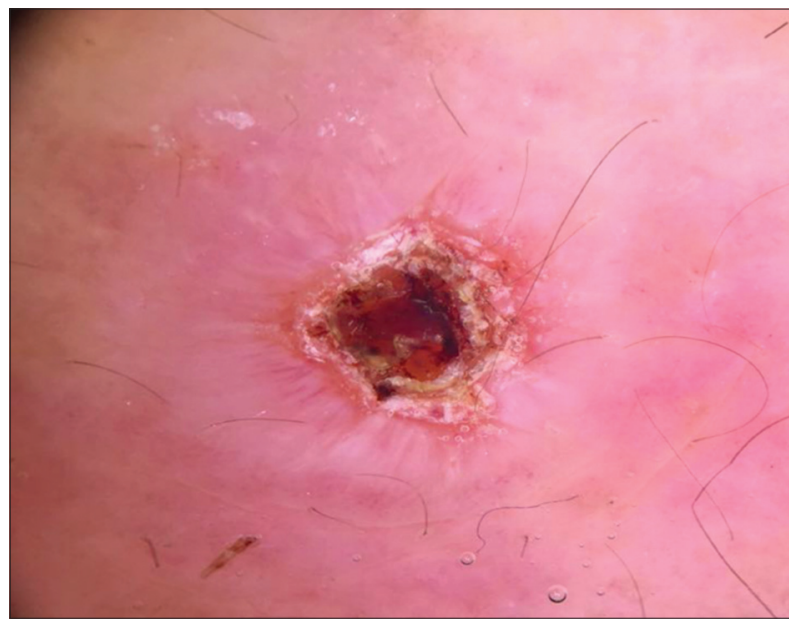

Figure 2: Dermoscopy of the nodule had projected an erythematous background, a white starburst-like pattern and a central ulceration.

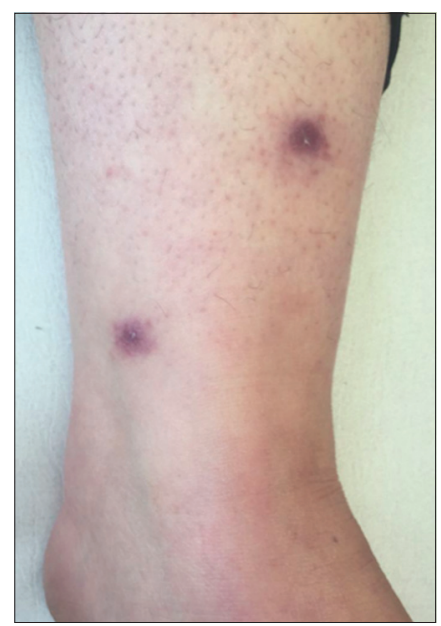

Figure 3: Erythematous plaques, well limited, finely scaly on legs.

is based on the combination of epidemiological, bacteriological and histological evidence. The biopsy shows tuberculoid granulomas with or without caseous necrosis [3]. Alcohol-acid-fast bacilli are absent or rare.

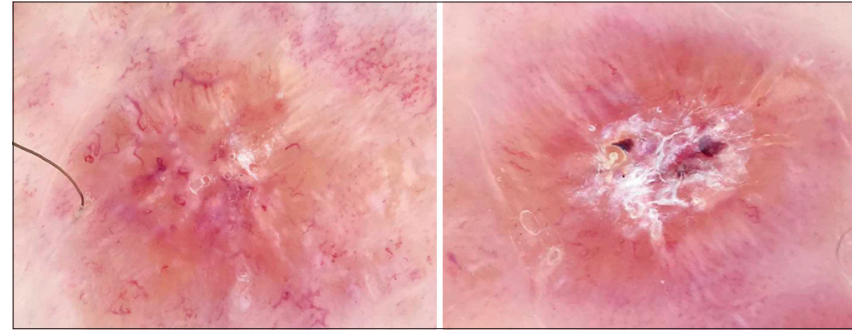

Figure 4: In dermoscopy: translucent orange globular areas, white starburst-like pattern' and vascular structures on the periphery, Arborizing, telangiectasia vessels, linear and hairpin, with ulceration and crusts.

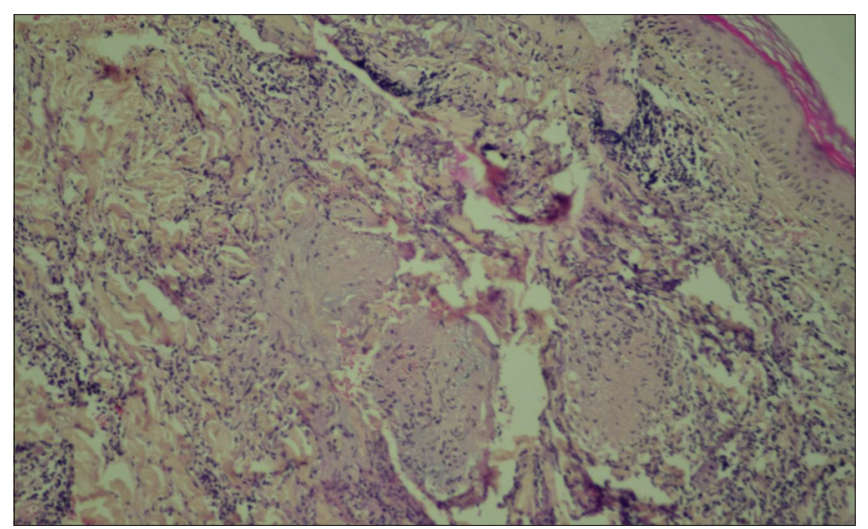

Figure 5: Histological section showing epithelioid cell granulomas with caseous necrosis.

The culture is frequently negative, and the tuberculin intradermoreaction is classically positive. The PCR takes its potential value in the pauci-bacillary forms where the diagnosis is more difficult [4]. In some cases, only the therapeutic test allows to "affirm" the diagnosis $[5,6]$. The treatment is similar to that of pulmonary tuberculosis. The clinical response is expected between four and six weeks after the start of treatment.

\section{CONCLUSION}

Cutaneous tuberculosis is an entity with multiple clinical and histological forms. The dermoscopy being nonspecific, it is necessary to think of it before any cutaneous lesion in the endemic countries.

\section{Consent}

The examination of the patient was conducted according to the Declaration of Helsinki principles.

The authors certify that they have obtained all appropriate patient consent forms. In the form the patient(s) has/have given his/her/their consent for 
his/her/their images and other clinical information to be reported in the journal. The patients understand that their names and initials will not be published and due efforts will be made to conceal their identity, but anonymity cannot be guaranteed.

\section{REFERENCES}

1. Benchikhi H, Chiheb S. Tuberculose cutanée EMC, Elsevier Masson, 2015.

2. Foo CC, Tan HH. A case of tuberculosis verrucosa cutis undiagnosed for 44 years and resulting in fixed-flexion deformity of the arm. Clin Exp Dermatol. 2005;30:149-51.

3. Kaufmann I, Kurz K. Comparison of tuberculosis cutis luposa and cutaneous leishmaniasis. Z Hautkr. 1985;60:9-39.

4. Tigoulet F, Fournier V, Caumes E. Formes cliniques de la tuberculose cutanée. Bull Soc Pathol Exot. 2003;96:362-7.

5. Sin C, Wann A-R, Grossin M, Courdavault L, Sigal M-L, et al. Tuberculose cutanée et érythème induré de Bazin: étude rétrospective de 13 cas. Ann Dermatol Venereol. 2015;142:237-44.

6. Chaabane H, Chami I, Charfi S, Masmoudi A, Amouri M, Makni S, et al. [Lesions of the nose revealing warty tuberculosis], Presse Med. 2015;44:372-3.

Copyright by Khadija Issoual, et al. This is an open access article distributed under the terms of the Creative Commons Attribution License, which permits unrestricted use, distribution, and reproduction in any medium, provided the original author and source are credited.

Source of Support: Nil, Conflict of Interest: None declared. 